\title{
Transillumination of the fingers for vascular anomalies: a novel method for evaluating hereditary hemorrhagic telangiectasia
}

\author{
Emile R. Mohler III, $M D^{I}$, Vijay Doraiswamy, $M D^{I}$, Alexandra Sibley, $B S^{I}$, \\ Barbara A. Bernhardt, $R N^{I}$, and Reed E. Pyeritz, $M D^{1,2}$
}

\begin{abstract}
Purpose: We describe a novel approach for detecting vascular abnormalities deep in the digits by means of a handheld illuminator. Methods: Ten patients with hereditary hemorrhagic telangiectasia were compared with 10 controls for telangiectases in the fingers using a handheld otoscope. Results: This noninvasive transillumination method revealed telangiectases in 9 of 10 patients with hereditary hemorrhagic telangiectasia and none in controls. Conclusions: Transillumination of fingers with an otoscope identifies telangiectases in patients with hereditary hemorrhagic telangiectasia. Further studies are needed to determine the prevalence of telangiectases in the finger and whether this finding is present in other vascular diseases. Genet Med 2009:11(5):356-358.
\end{abstract}

Key Words: hereditary hemorrhagic telangiectasia, congenital vascular anomaly, transillumination, finger, telangiectases

$\mathrm{H}$ ereditary hemorrhagic telangiectasia (HHT), also known as Osler-Weber-Rendu syndrome, is a multisystem vascular dysplasia characterized by arteriovenous malformations (AVMs). ${ }^{1,2}$ The overall incidence of HHT in North America is estimated at about 1 in 5000. From its first documentation in the 19th century, HHT was recognized as a familial disorder with mucosal and skin telangiectases, epistaxis, and gastrointestinal bleeding. ${ }^{1,3}$ Later, additional abnormal vessels were described in HHT, mostly AVMs of the pulmonary, hepatic, and cerebral circulations. ${ }^{4}$ Morbidity results from chronic blood loss, cyanosis due to pulmonary AVMs, paradoxical embolization causing stroke or brain abscess, stroke from cerebral AVMs, hepatic failure, and high-output cardiac failure.

The diagnosis of HHT remains largely based on clinical criteria, ${ }^{5}$ although molecular testing of three causative genes can be helpful, especially for asymptomatic family members if the familial mutation has been identified. Bedside evaluation is complicated by several issues. First, many of the features of HHT are age-dependent, so younger patients may have few outward signs. Second, telangiectases may be confused with other vascular lesions, and occur in people in the general population, especially in sun-exposed areas of the skin. A simple, noninvasive technique for evaluating for telangiectases in the fingers may herald the diagnosis of HHT. We describe an approach for detecting vascular abnormalities deep in the digits by means of a handheld illuminator.

From the Departments of ${ }^{1}$ Medicine and ${ }^{2}$ Genetics, University of Pennsylvania School of Medicine, Philadelphia, Pennsylvania.

Emile R. Mohler III, MD, Hospital of the University of Pennsylvania, 4th Floor Penn Tower Building, 3400 Spruce Street, Philadelphia, PA 19104. E-mail: mohlere@uphs.upenn.edu.

Disclosure: The authors declare no conflict of interest.

Submitted for publication November 19, 2008

Accepted for publication December 23, 2008.

DOI: $10.1097 /$ GIM.0b013e31819b245a

\section{MATERIALS AND METHODS}

\section{Patient selection}

After approval from the Institutional Review Board, 10 consecutive adult patients referred for initial evaluation at the University of Pennsylvania HHT Center, administered by the Division of Medical Genetics, were approached for enrollment. All were diagnosed with HHT based on the international consensus diagnostic criteria for HHT (minimum of three of four criteria met). ${ }^{5}$ As a part of their evaluation, all subjects underwent a contrast echocardiogram and if it was positive for late passage of contrast to the left atrium, a CT angiogram of the lungs was performed for assessment of pulmonary AVMs. An MRI of the brain was also recommended; this was often carried out after the initial visit to the HHT Center. A control group consisting of persons matched for age and gender, and who met none of the diagnostic criterion was also enrolled. Informed consent was obtained from all subjects participating in the study.

\section{Transillumination of the digits}

In a dark room with the patient seated and the hand supinated, an otoscope with a Halogen $3.5 \mathrm{~V}$ bulb was placed on the dorsum of each finger sequentially. The tip of the otoscope was placed in contact with the skin to prevent escape of light. The otoscope was slowly moved from the metacarpophalangeal joint to the tip of the finger. Vascular anomalies such as telangiectases, dilatation, and excessive tortuosity were noted. The fingers were each evaluated in ambient light and note made of cutaneous telangiectases. Pictures were obtained with a Cannon 35-mm camera.

\section{Duplex ultrasound of the digits}

To assess the blood flow in the fingers, Duplex ultrasound was performed with an $8-\mathrm{MHz}$ transducer (Siemens). A sagittal view of each finger was examined using color Doppler ultrasound.

\section{RESULTS}

The patient characteristics are listed in Table 1 . The majority of subjects with HHT were female and white. As expected, patients with HHT had a strong family history of this condition.

When patients with HHT were evaluated with transillumination, dark oval spots were seen with a background of red illumination through the fingers (Fig. 1). These are present even when the light source is moved laterally to the fingers $\left(90^{\circ}\right.$ to previous plane of light) confirming their relationship to a vessel. Some dark spots in HHT and control subjects disappeared once the light was moved to a different plane; a common example was graphite from a wound of a pencil. Some vascular anomalies, 3-4 $\mathrm{mm}$ in diameter, occurred in a linear array, as in beads on a string. Of the subjects with HHT, 9 of 10 had 


\begin{tabular}{|c|c|c|}
\hline Features & $\begin{array}{l}\text { HHT patients } \\
\quad(n=10)\end{array}$ & $\begin{array}{l}\text { Normal controls } \\
\quad(n=10)\end{array}$ \\
\hline Age range (yr) & $31-69$ & $28-69$ \\
\hline Gender (female:male) & $9: 1$ & $9: 1$ \\
\hline Race & 10 Whites & 8 Whites, 2 Asians \\
\hline \multicolumn{3}{|l|}{ Family history of HHT } \\
\hline Parent & 7 & 0 \\
\hline Child & 5 & 0 \\
\hline Diagnostic criteria & $\begin{array}{l}4 \text { of } 4 \text { criteria } \\
\text { present-7 } \\
3 \text { of } 4 \\
\text { criteria } \\
\text { present-3 }\end{array}$ & 0 of 4 criteria present 10 \\
\hline $\begin{array}{c}\text { Pulmonary AVMs } \\
\text { present }\end{array}$ & 7 of 10 & - \\
\hline $\begin{array}{c}\text { Hepatic AVMs } \\
\text { present }\end{array}$ & 3 of 7 & - \\
\hline $\begin{array}{c}\text { Brain AVMs } \\
\text { present }\end{array}$ & 0 of 4 & - \\
\hline
\end{tabular}

AVM, arteriovenous malformations; HHT, hemorrhagic telangiectasia.

vascular anomalies in at least one finger that was not evident from examination of the skin. None of the controls had any evidence for vascular abnormalities of the digits. All telangiectases that were evident on visual inspection of the skin surface were also evident on transillumination.

Color Doppler ultrasound showed dilated veins and arteries in close proximity in the region of the lesions seen on transillumination, consistent with the dark spots being small AVMs.

\section{DISCUSSION}

HHT is an autosomal dominant disorder of vasculogenesis with variable expression because of heterozygous mutations in one of at least six genes. ${ }^{2}$ Two major disease genes are on chromosome 9 ( $E N G$, which encodes endoglin, a coreceptor for TGF- $\beta$, and bone morphogenic protein cytokines) and chromosome 12 (ACVRL1, which encodes activin receptor-like kinase 1 , also called ALK-1). A third gene, SMAD4, which encodes an intracellular signaling intermediary in the TGF- $\beta$ and BMP cascade, when mutated causes HHT associated with juvenile polyps. Several other genes have been mapped but not identified. ${ }^{2}$ Clinical molecular testing is useful in confirming the diagnosis of HHT in probands when clinical features are equivocal, and especially in relatives of probands who can be tested for the familial mutation. ${ }^{6}$

Vascular malformations occur in HHT in many tissues and organs, and can be small, as with mucocutaneous telangiectases, or large as in AVMs in the lungs, liver, and brain. ${ }^{7,8}$ Thirty to $40 \%$ of patients have pulmonary and hepatic AVMs, and $10-$ $20 \%$ have cerebral AVMS; when larger than 2-3 mm, they are easily detected by MR or CT. Telangiectases of the skin, buccal mucosa, and gastrointestinal mucosa occur in about $75 \%$ of individuals and become more numerous and larger with age. Small lesions of the digital nail beds can be viewed by capillaroscopy, 9,10 and this approach has been advanced as an aid to diagnosis when clinical criteria are minimal. Unfortunately, the
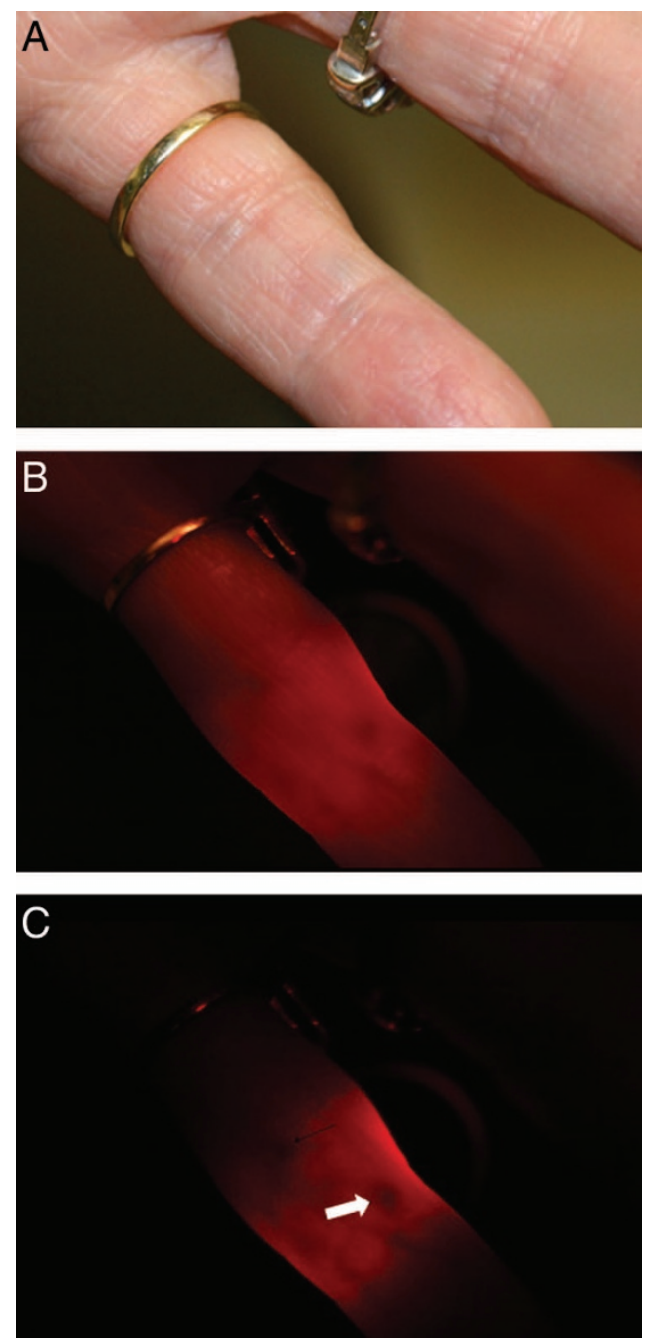

Fig. 1. A, External surface of fifth digit of patient with HHT taken with room lighting. B, Same finger with darker light using otoscope transillumination. Dark spots are seen indicating telangiectases. C, Same finger with no room lighting. Telangiectases are revealed as dark oval spots (arrows) and are better delineated on the palmar aspect of the finger with darker environment.

equipment and expertise for capillaroscopy are not readily available in outpatient settings.

AVMs deep in the fingers are being reported for the first time in our study. These AVMs are seen with or without superficial telangiectases and were present in 9 of 10 HHT patients. An interesting feature of these AVMs when compared with artifacts of control group is that, when the light source is moved laterally to a different plane, the spherical shape of the anomalies is maintained. The dark spots seen in a normal person may be due to differences in the tissue thickness, overlapping vessels, and foreign bodies; they disappear once the plane of the light is changed. Thus, when examining the fingers for telangiectases, it is important to transilluminate in more than one plane to avoid false-positive findings. Doppler study of digits containing anomalies shows close proximity of dilated arteries and veins.

Patients with HHT occasionally have bleeding from trauma because of superficial digital telangiectases, but have not re- 
ported complications from hemorrhages of the deeper anomalies that are detectable by transillumination. The detection of these anomalies could be useful in the diagnosis of HHT in a clinical setting by means of a focused, bright light source, such as an otoscope.

\section{Limitations}

HHT is an uncommon disease and because of this our sample population was only 10 patients. Our HHT subjects were all whites and did not involve a diverse racial sample. The study control group did not have imaging to evaluate for internal vascular problems, such as AVMs, but there was no clinical suspicion of such lesions. Even though most of the subjects with HHT had pulmonary AVMs, a larger study is needed to explore the relationship between digital vascular anomalies and other manifestations of HHT. Our sample population consisted of mostly females. Persons with thick skin may not be as amenable to transillumination as the intensity of the standard otoscope may not enable penetration of the digit.

\section{CONCLUSIONS}

Transillumination of fingers with an otoscope identifies telangiectases in patients with HHT. Further studies are needed to determine the prevalence of telangiectases in the finger and whether this finding is present in other vascular diseases.

\section{ACKNOWLEDGMENTS}

The authors thank Joanne Ngo for her technical assistance with ultrasound images.

\section{REFERENCES}

1. Osler W. On a family form of recurring epistaxis, associated with multiple telangiectases of the skin and mucous membranes. Bull Johns Hopkins Hosp 1901;12:333-337.

2. Guttmacher A, Marchuck D, Pyeritz RE. Hereditary hemorrhagic telangiectasia. In: Rimoin DL, Connor JM, Pyeritz RE, Korf BR, editors. Principles and practice of medical genetics, 5th ed. Philadelphia: Churchill Livingstone, 2007:1200-1213.

3. Sutton HG. Epistaxis as an indication of impaired nutrition, and of degeneration of the vascular system. Med Mirror 1864;1:769.

4. Smith JL, Lineback MI. Hereditary hemorrhagic telangiectasia; nine cases in one Negro family, with special reference to hepatic lesions. Am J Med 1954;17:41-49.

5. Shovlin CL, Guttmacher AE, Buscarini E, et al. Diagnostic criteria for hereditary hemorrhagic telangiectasia (Rendu-Osler-Weber syndrome). Am J Med Genet 2000;91:66-67.

6. Cohen JH, Faughnan ME, Letarte M, Vandezande K, Kennedy SJ, Krahn MD. Cost comparison of genetic and clinical screening in families with hereditary hemorrhagic telangiectasia. Am J Med Genet A 2005;137:153-160.

7. Roman G, Fisher M, Perl DP, Poser CM. Neurological manifestations of hereditary hemorrhagic telangiectasia (Rendu-Osler-Weber disease): report of 2 cases and review of the literature. Ann Neurol 1978;4:130-144

8. Mohler ER, Monahan B, Canty MD, Flockhart DA. Cerebral abscess associated with dental procedure in hereditary haemorrhagic telangiectasia. Lancet 1991;338:508-509.

9. Mager JJ, Westermann CJ. Value of capillary microscopy in the diagnosis of hereditary hemorrhagic telangiectasia. Arch Dermatol 2000;136:732-734.

10. Pasculli G, Quaranta D, Lenato GM, et al. Capillaroscopy of the dorsal skin of the hands in hereditary hemorrhagic telangiectasia. QJM 2005;98:757-763. 